\title{
Caracterização Fisiológica, Cultural e Patogênica de Diferentes Isolados de Lasiodiplodia theobromae
}

\author{
Aurenice L. Pereira ${ }^{1}$, Gilson S. Silva ${ }^{1}$ \& Valdenir Q. Ribeiro ${ }^{2}$ \\ ${ }^{1}$ Departamento de Fitotecnia e Fitossanidade, Universidade Estadual do Maranhão, CEP 65001-970, \\ São Luís, MA, e-mail: gilson_soares@uol.com.br; ²Embrapa Meio Norte, Cx. Postal 01, CEP 64006-220, Terezina, PI
}

(Aceito para publicação em 12/12/2006)

Autor para correspondência: Gilson Soares da Silva

PEREIRA, A.L., SILVA, G.S \& RIBEIRO, V.Q. Caracterização fisiológica, cultural e patogênica de diferentes isolados de Lasiodiplodia theobromae. Fitopatologia Brasileira 31:572-578. 2006.

\section{RESUMO}

Lasiodiplodia theobromae é responsável por doenças em inúmeras plantas cultivadas, causando perdas significativas de produção, notadamente no Nordeste brasileiro. Estudos básicos sobre esse fungo são necessários para se compreender melhor as interações patógeno-hospedeiro e traçar estratégias de controle. Este trabalho teve como objetivo caracterizar oito isolados de L. theobromae, obtidos de diferentes hospedeiros, quanto ao crescimento micelial, produção e fertilidade de picnídios, aspectos morfológicos das colônias e patogenicidade. Os isolados variaram em todas as características estudadas. O meio aveia-ágar proporcionou a maior produção e fertilidade de picnídios, sobressaindo-se os isolados obtidos de manga e maracujá. O meio cenoura-ágar não promoveu a produção dessas estruturas. Quanto ao crescimento micelial, o meio V-8 promoveu maior velocidade de crescimento dos isolados. Em relação à coloração da colônia houve grande variação, predominando a coloração branco-acinzentada. Quanto à formação dos picnídios, verificou-se que a maioria dos isolados formaram tais estruturas. Em ensaios de inoculação cruzada, todos os isolados mostraram-se patogênicos aos hospedeiros testados.

Palavras-chave adicionais: fisiologia, nutrição, patogenicidade.

\begin{abstract}
Physiological, cultural and pathogenic characterization of different isolates of Lasiodiplodia theobromae

Lasiodiplodia theobromae is responsible for diseases in several cultivated plants, causing significant losses in production, particularly among fruit trees in the Brazilian Northeast. Basic studies on this fungus are necessary to understand better the pathogen-host interactions and to trace control strategies. This work aimed to characterize eight isolates of $L$. theobromae from different hosts, accessing the mycelial growth, pycnidium production and fertility, morphological aspects of the colonies and pathogenicity. The isolates varied in all the characteristics studied. The culture medium of oatmeal agar provided best pycnidium production and fertility, with the isolate obtained from mango and passion fruit standing out. The culture medium of carrot agar did not provide pycnidium production. With relation to mycelial growth, V-8 juice medium was the culture medium which provided fastest mycelial growth. Coloration of the colony varied across a wide range, with white-gray coloration prevailing. As to the formation of pycnidia, it was verified that most of the isolates formed pycnidia. Assays evaluating pathogenicity by cross inoculation revealed that all isolates were pathogenic against all tested host plants.
\end{abstract}

Additional keywords: physiology, nutrition, pathogenicity.

\section{INTRODUÇÃO}

Lasiodiplodia theobromae (Pat.) Griffon \& Maubl. (syn. Botryodiplodia theobromae Pat.) é considerado um patógeno fraco (Holliday, 1980), mas nos últimos anos vem se tornando importante para diversas culturas. Atualmente, L. theobromae é responsável por doenças importantes em mangueira (Mangifera indica L.), coqueiro (Cocos nucifera L.), cajueiro (Anacardium occidentale L.), Spondias spp., dentre outras (Freire \& Cardoso, 2003). Levantouse a hipótese que $L$. theobromae tenha evoluído em patogenicidade em conseqüência das pressões ambientais, especialmente nas regiões semi-áridas, onde as condições climáticas lhes são muito favoráveis (Tavares, 2002).
Nestes ecossistemas, o fungo infecta várias culturas, causando doenças importantes, como a morte descendente do cajueiro (Freire \& Cardoso, 2003), do cacaueiro (Theobromae cacao L.), do guaranazeiro (Paullinia cupana Ducke), da mamoneira (Ricinus communis L.), da gravioleira (Annona muricata L.) e da ateira (Annona squamosa L.) (Ponte, 1985). Outros sintomas apresentados são murcha, podridão basal de frutos, cancro de tronco e de ramos da mangueira (Tavares, 2002). Levantamentos mais recentes, conduzidos pela Embrapa Agroindústria Tropical, revelaram um aumento no número de hospedeiros e na severidade do ataque desse patógeno (Freire et al., 2004).

Lasiodiplodia theobromae é um fungo cosmopolita, polífago e oportunista, com pouca especialização patogênica 
e, por conseguinte, é geralmente associado à processos patogênicos em plantas estressadas e submetidas a ferimentos naturais ou provocados por insetos, pássaros, primatas nativos e pelo próprio homem, através de práticas culturais (Olunloyo \& Esuruoso, 1975; Punithaligam, 1976; Prakassh \& Raoof, 1989; Tavares et al., 1994).

A sua capacidade de infectar frutos coloca-o dentre os mais eficientes patógenos disseminados por meio de sementes e causadores de problemas pós-colheita (Freire et al., 2004), o que vem proporcionando a disseminação desse fungo e o aparecimento de doenças como a podridão-secada-haste em anonáceas, uma vez que a propagação destas é realizada por meio de sementes (Sales Júnior, 2004).

O controle dessas doenças torna-se difícil em razão da enorme gama de hospedeiros apresentada pelo fungo. $\mathrm{O}$ controle químico por si só não oferece proteção nem controle curativo da cultura ao L. theobromae, sendo então indicado a adoção de uma série de medidas adicionais como o manejo cultural e o controle biológico (Tavares, 1995).

A variação nas características morfológicas e fisiológicas entre isolados de $L$. theobromae provenientes de diferentes hospedeiros e regiões geográficas é conhecida por vários autores. Ao avaliar as características culturais, desenvolvimento micelial, esporulação, morfologia e patogenicidade de dez isolados de $B$. theobromae de diferentes hospedeiros, Ram (1993), verificou que os isolados variaram na coloração da colônia e no crescimento micelial.

Menezes et al. (1997), em estudos com L. theobromae em mamoeiro (Carica papaya L.), observaram que o fungo isolado em BDA, a partir da podridão da haste, apresentou colônia inicialmente branca, tornando-se de coloração cinzaesverdeada a preta, com micélio aéreo vigoroso e de aspecto algodonoso, extensão micelial rápida, cobrindo toda a superfície da placa em $48 \mathrm{~h}$.

Estudando diferentes isolados obtidos de cacaueiro, mamoneira, roseira (Rosa spp.), gravioleira, maracujazeiro (Passiflora edulis L.), laranjeira (Citrus spp.), mangueira e coqueiro, Ram (1993) constatou que os isolados de $L$. theobromae de diferentes culturas, variam em características culturais, esporulação e patogenicidade.

Ao avaliar o crescimento micelial, produção de picnídios e picnidiósporos de $B$. theobromae oriundo de lesões em ramos de plantas cítricas, Moraes et al. (1995) utilizaram meios de decocção de folhas de tangerineira (Citrus spp.) 'Murcot' e 'Ponkan' em comparação com meios tradicionais. Os autores observaram que houve grande variação do fungo nos meios utilizados, sendo que os meios BDA e Malte-ágar promoveram maior crescimento micelial.

De modo geral, os microrganismos apresentam como característica uma grande variabilidade que pode refletir em sua morfologia, fisiologia ou patogenicidade. Variações na capacidade de utilização de diferentes substratos, de tolerância a determinados valores e faixas de temperatura e $\mathrm{pH}$, de produção de toxinas ou outros metabólitos, que são manifestações de diferenças fisiológicas dentro de uma população, resultam, às vezes, em variações na patogenicidade dos biótipos
(Machado, 1980).

Considerando-se que isolados de $L$. theobromae originados de diferentes áreas geográficas e hospedeiros apresentam variações nas características morfológicas e fisiológicas, comportando-se de maneira distinta quanto ao crescimento, esporulação e patogenicidade de acordo com o substrato utilizado para seu crescimento e o hospedeiro de origem, faz-se necessário o conhecimento desses dados que servirão de subsídios para pesquisas que visem minimizar os prejuízos causados por este patógeno em diversas culturas, através de métodos de controle menos agressivos ao meio ambiente. Por estes motivos, o presente trabalho teve como objetivo caracterizar isolados de L. theobromae obtidos de diversos hospedeiros, avaliando a patogenicidade e o efeito de diferentes substratos sobre a produção e fertilidade de picnídios, crescimento micelial, coloração, aspecto da colônia e formação dos picnídios.

\section{MATERIAL E MÉTODOS}

Foram utilizados oito isolados de L. theobromae coletados no Estado do Maranhão e posteriormente identificados quanto ao hospedeiro e local de coleta. Todos os isolados apresentaram características morfológicas típicas da espécie L. theobromae, de acordo com Sutton (1980). Os isolados foram numerados de 1 a 8 , na seguinte ordem: 1- isolado de caju do município de Caxias; 2 - isolado de caju do município de Imperatriz; 3 - isolado de mangueira do município de Itinga; 4, 5 e 6 - isolados de maracujá de São Luís; 7 - isolado de coco do município de Cedral e 8 - isolado de mamoeiro de São Luís.

Para instalação dos experimentos, os isolados foram transferidos para placas de Petri contendo meio batatadextrose-ágar (BDA) e incubados em estufa tipo B.O.D. a 25 $\pm 1{ }^{\circ} \mathrm{C}$, com $12 \mathrm{~h}$ de fotoperíodo por 5 dias e, posteriormente, conservados em tubos de ensaio com o mesmo meio, em geladeira a $5{ }^{\circ} \mathrm{C}$.

Influência de meios de cultura sobre o crescimento micelial, produção e fertilidade de picnídios, e características culturais de isolados de Lasiodiplodia theobromae

Os meios de cultura utilizados para estes ensaios foram: a) BDA (Batata, 200g; dextrose, 20g; ágar, 17g; água destilada, $1000 \mathrm{~mL}$ ); b) CA (cenoura, 20g; ágar, 17g; água destilada, $1000 \mathrm{~mL}$ ); c) AvA (flocos de aveia, 75g; ágar, 17g; água destilada, $1000 \mathrm{~mL}$ ); d) FA (fubá de milho, 60g; ágar, $17 \mathrm{~g}$; água destilada, $1000 \mathrm{~mL}$ ); e) V-8 (suco V-8, 200mL; $\mathrm{CaCO}_{3}, 3 \mathrm{~g}$; ágar, $17 \mathrm{~g}$; água destilada, $800 \mathrm{~mL}$ ).

A partir de culturas puras dos oito isolados de $L$. theobromae, mantidos em placas de Petri contendo meio de cultura BDA, sob regime de luz de $12 \mathrm{~h}$ de fotoperíodo com cinco dias de idade, foram retirados, das bordas da colônia, discos de aproximadamente $5 \mathrm{~mm}$ de diâmetro contendo estruturas dos isolados e depositados no centro da placa contendo $20 \mathrm{~mL}$ dos diferentes meios, e em seguida, 
incubados em estufa B.O.D. a $25 \pm 1^{\circ} \mathrm{C}$ com alternância de luz/escuro de $12 \mathrm{~h}$.

A avaliação do crescimento micelial consistiu da leitura, a cada 24 h, do diâmetro da colônia em dois sentidos diametralmente opostos, definindo-se uma média para cada repetição. As leituras foram concluídas quando o crescimento da colônia cobriu completamente o diâmetro da placa em um dos tratamentos, determinando-se a velocidade média de crescimento do fungo, através da fórmula adaptada de Lilly \& Barnett (1951).

$$
\mathrm{Vmc}=\underline{\mathrm{Ct}}_{\frac{2}{\mathrm{~T}}}-\mathrm{Ct}_{1} \quad \text { onde, }
$$

$\mathrm{Vmc}=$ velocidade média de crescimento;

$\mathrm{Ct}_{1}=$ crescimento no primeiro intervalo de tempo;

$\mathrm{Ct}_{2}=$ crescimento no segundo intervalo de tempo;

$\mathrm{T}=$ intervalo de tempo considerado.

A produção de picnídios foi determinada através da contagem dessas estruturas sob lupa estereoscópica, onde foram contados todos os picnídios formados em cada um dos isolados e meios, após 15 dias de incubação. Para determinar a fertilidade, foram considerados férteis os picnídios que apresentaram exsudatos de esporos na sua superfície.

As características culturais foram avaliadas, após 15 dias de incubação, considerando-se o aspecto visual das colônias quanto à cor e modo de formação dos picnídios, se isolados ou dispersos, se submersos ou superficiais.

Odelineamento estatístico utilizado foi inteiramente casualizado em arranjo fatorial $8 \times 5$ (isolados $\mathrm{x}$ meios de cultura) em um total de quarenta tratamentos com três repetições cada.

Os dados obtidos para o crescimento micelial não sofreram transformação, enquanto para produção e fertilidade de picnídios foram transformados para $(\mathrm{X}+$ $0,5)^{0,5}$ sendo as médias comparadas por meio do teste de Tukey, ao nível de $5 \%$ de probabilidade.

\section{Teste de inoculação cruzada}

Testou-se a patogenicidade dos isolados de $L$. theobromae em ensaios de inoculação cruzada nas frutíferas de coco, caju, manga, maracujá e mamão. Os frutos depois de lavados com água e sabão foram desinfestados em uma solução de hipoclorito de sódio a $1 \%$ por 10 min e em seguida lavados com água corrente e deixados secar ao ar. A inoculação foi realizada através da deposição de disco de meio BDA contendo estruturas do fungo na superfície do fruto previamente ferido com estilete flambado. Em seguida, os frutos foram mantidos em câmara úmida por 72 hs, em condições de laboratório, a aproximadamente $28^{\circ} \mathrm{C}$.

A patogenicidade dos isolados foi avaliada $72 \mathrm{~h}$ após a inoculação, através de uma escala de notas adaptada de Lima (1996), que varia de 0 a 4 determinada com base na severidade da doença: (1- lesões com menos de $1 \mathrm{~cm}$ de diâmetro $=$ resistente; 2 - lesões com até $2 \mathrm{~cm}$ de diâmetro
$=$ medianamente resistente; 3 - lesões profundas com mais de $2 \mathrm{~cm}$ de diâmetro = suscetível; 4 - abundante cobertura micelial e apodrecimento $=$ altamente suscetível).

\section{RESULTADOS E DISCUSSÃO}

\section{Influência de meios de cultura sobre o crescimento micelial de isolados de Lasiodiplodia theobromae}

Os isolados variaram em todas as características avaliadas. Em relação ao crescimento micelial de isolados de L. theobromae em diferentes meios de cultura, verificouse que o fitopatógeno utilizou de maneira mais eficiente o meio V- 8, pois este proporcionou maior velocidade de crescimento micelial para todos os isolados, com exceção do isolado 3 (manga), que apresentou maior velocidade de crescimento no meio AvA (Tabela 1).

Os meios AvA e BDA promoveram um bom desempenho na taxa de crescimento micelial, destacandose dos meios FA e CA, que proporcionaram, na maioria dos isolados, as menores taxas de crescimento, contrariando os resultados encontrados por Lima (1996), nos quais se destacaram os meios CDA (cenoura-dextrose-ágar), BDA (batata-dextrose-ágar), MDA (fubá de milho-dextroseágar) e SDA (soja-dextrose-ágar), como os melhores para promover o crescimento micelial de isolados de ramos de mangueira.

Ao se comparar os meios BDA e AvA, observou-se que AvA foi mais eficaz para a maioria dos isolados, porém não diferindo estatisticamente. Resultados semelhantes foram encontrados por Sousa Filho et al. (1979) que verificaram a superioridade do meio AvA sobre os meios BDA, Czapeck, malte-ágar e bacto-ágar no crescimento de isolados obtidos de folhas de coqueiro. Ram (1993), ao estudar isolados de B. theobromae de vários hospedeiros também observou que o meio de AvA, foi mais eficaz do que os meios extrato-de malte e extrato de levedura + malte.

Em relação aos isolados do fungo, verificou-se que o isolado 6 (maracujá), apresentou maior taxa de crescimento micelial em quase todos os meios, com exceção dos meios CA e V- 8, sendo este último melhor aproveitado pelo isolado 7 (coco). Os isolados 1 e 2 (caju), 5 (maracujá) e 7 (coco) apresentaram crescimento micelial satisfatório, não diferindo estatisticamente entre si. Os isolados 3 (manga) e 8 (mamão) mostraram-se os mais lentos em crescimento quando cultivados nos meios BDA, V- 8, FA e CA.

A grande variação entre isolados, referente ao aproveitamento dos meios de cultura, também foi verificada nos trabalhos de Sousa Filho et al. (1979), Ram (1993) e Lima (1996). Em trabalhos desenvolvidos para muitos fungos, Lilly \& Barnett (1951) concluíram que os meios naturais ou semi-sintéticos fornecem certas substâncias que funcionam como fatores estimuladores do crescimento. Os valores relativamente altos para velocidade média de crescimento de alguns isolados nos meios $\mathrm{V}-8$, AvA e BDA, demonstraram uma adequação do substrato às exigências fisiológicas do fungo. 
Caracterização fisiológica, cultural e patogênica de diferentes isolados...

TABELA 1 - Taxa de crescimento micelial de oito isolados de Lasiodiplodia theobromae em cinco diferentes meios de cultura

\begin{tabular}{llcccl}
\hline \multicolumn{5}{c}{ Taxa de crescimento micelial (cm/dia)* } \\
\hline \multicolumn{5}{c}{ Meios de Cultura** } \\
\hline Isolados & BDA & $\mathbf{V - 8}$ & AvA & FA & CA \\
\hline 1 Caju & $4,00 \mathrm{Cbc}$ & $5,66 \mathrm{Ab}$ & $4,66 \mathrm{BCabc}$ & $4,26 \mathrm{Ca}$ & $5,33 \mathrm{Aba}$ \\
2 Caju & $3,66 \mathrm{Cc}$ & $6,43 \mathrm{Aab}$ & $4,90 \mathrm{Bab}$ & $4,13 \mathrm{Ca}$ & $5,23 \mathrm{Ba}$ \\
3 Manga & $2,66 \mathrm{Bd}$ & $3,90 \mathrm{Ad}$ & $4,06 \mathrm{Acd}$ & $2,66 \mathrm{Bb}$ & $3,00 \mathrm{Bcd}$ \\
4 Maracujá & $3,90 \mathrm{Bbc}$ & $4,83 \mathrm{Ac}$ & $3,53 \mathrm{BCde}$ & $3,06 \mathrm{Cb}$ & $3,23 \mathrm{BCcd}$ \\
5 Maracujá & $4,70 \mathrm{BCab}$ & $5,66 \mathrm{Ab}$ & $4,93 \mathrm{ABab}$ & $4,43 \mathrm{BCa}$ & $4,13 \mathrm{Cb}$ \\
6 Maracujá & $5,43 \mathrm{Aa}$ & $6,00 \mathrm{Aab}$ & $5,30 \mathrm{Aba}$ & $4,63 \mathrm{Ba}$ & $3,80 \mathrm{Cbc}$ \\
7 Coco & $3,96 \mathrm{BCbc}$ & $6,60 \mathrm{Aa}$ & $4,40 \mathrm{Bbc}$ & $4,23 \mathrm{BCa}$ & $3,63 \mathrm{Cbcd}$ \\
8 Mamão & $3,66 \mathrm{Bc}$ & $4,50 \mathrm{Acd}$ & $3,00 \mathrm{BCe}$ & $2,83 \mathrm{Cb}$ & $2,96 \mathrm{BCd}$ \\
\hline CV=7,52 & \multicolumn{5}{c}{}
\end{tabular}

*Médias de três repetições por tratamento. Médias seguidas das mesmas letras minúsculas (colunas) e maiúsculas (linhas) não diferem entre si estatisticamente pelo teste de Tukey ao nível de $5 \%$ de probalidade.

**BDA = batata-dextrose-ágar; V-8 = suco V-8-CaCO 3 -ágar; AvA = flocos de aveiaágar; $\mathrm{FA}=$ fubá de milho-ágar; $\mathrm{CA}=$ suco de cenoura-ágar.

\section{Influência de meios de cultura sobre a produção e fertilidade de picnídios de isolados de Lasiodiplodia theobromae}

Os resultados mostraram significativa variação dos isolados quanto à produção e fertilidade de picnídios nos diferentes meios de cultura (Tabelas 2 e 3 ). O melhor meio de cultura para a produção de picnídios para a maioria dos isolados foi AvA, seguido por FA, BDA e V-8. No meio AvA os isolados 3 (manga) e 5 (maracujá) apresentaram a maior produção de picnídios e os isolados 1 (caju) e 7 (coco) as menores. O isolado 1 (caju) produziu mais picnídios no meio FA; o isolado 3 (manga) em AvA e BDA; e o isolado 7 (coco) em AvA, BDA, FA e V-8. Embora FA tenha sido o melhor meio parar o isolado 1, AvA pode ser utilizado também para este isolado pois a quantidade de picnídios produzida foi igual à do isolado 7 nesse mesmo meio (Tabela 2).

Com relação à influência dos diferentes meios na produção de picnídios verificou-se que o meio CA não se mostrou eficaz, não favorecendo a produção dessas estruturas em nenhum isolado, fato que levou a exclusão deste meio nas análises estatísticas. A eficácia de AvA em relação aos outros meios de cultura testados para a produção de picnídios é confirmada pelos resultados obtidos por Alasoadura (1970) e Lima (1996).

Quanto à fertilidade dos picnídios, o meioAvAtambém foi o melhor para a maioria dos isolados, destacando-se o isolado 5 (maracujá) como o mais fértil. No geral, o isolado 7 (coco), foi o menos fértil, no entanto, no meio BDA, apresentou a maior fertilidade, diferindo estatisticamente dos demais isolados. Os isolados 1 e 2 de (caju), na maioria dos casos, comportaram-se de maneira semelhante apresentando baixa fertilidade, não diferindo estatisticamente nos meios FA, BDA e V-8 (Tabela 3).

Rodriguez \& Mattos (1988) relataram que a formação e quantidade de picnídios são variáveis em função do meio de cultura utilizado. É cada vez mais freqüente o interesse de pesquisadores que estudam a fisiologia de fungos, através da avaliação da fertilidade de picnídios. Trabalhos conduzidos por Kurozawa \& Balmer (1997) revelaram que a fertilidade é um parâmetro completamente desvinculado do número de picnídios produzidos e que o aumento na produção destas estruturas, por si só, não traduzem no potencial reprodutivo dos fungos, de modo que, ao se estudar o processo reprodutivo, torna-se de maior importância a avaliação da fertilidade.

Mattos \&Ames (1986), em estudos com B. theobromae afetando macieira (Malus spp.), observaram que os meios em que o fungo desenvolveu maior crescimento micelial, houve pouca esporulação, enquanto que os meios em que houve menor crescimento micelial, promoveram abundante esporulação. Com base nesses resultados, concluíram que o crescimento micelial é maior, à medida que aumenta a quantidade de carboidratos, e menores quantidades favorece a frutificação e esporulação. Este fato pode ser verificado no presente trabalho, quando se conclui que o melhor meio para crescimento foi o V- 8, enquanto que o melhor meio para frutificação foi o meio AvA.

O modo de aproveitamento dos nutrientes pelos fungos é outro dado interessante, uma vez que houve uma grande diferença no que se refere ao crescimento e esporulação. $\mathrm{O}$ isolado 3 (manga) foi o que apresentou maior esporulação, porém, menor crescimento micelial, enquanto que o isolado 6 (maracujá), não apresentou esporulação e, no entanto, foi 
TABELA 2 - Produção de picnídios de isolados de Lasiodiplodia theobromae em diferentes meios de cultura

\begin{tabular}{llllll}
\hline \hline \multicolumn{5}{c}{ Número total de picnídios* } \\
\hline $\begin{array}{c}\text { Meios } \\
\text { de }\end{array}$ & \multicolumn{5}{c}{ Isolados } \\
\cline { 2 - 6 } Cultura** & $\mathbf{1}$ & $\mathbf{2}$ & $\mathbf{3}$ & $\mathbf{5}$ & $\mathbf{7}$ \\
\hline AvA & $6,53 \mathrm{bC}$ & $9,72 \mathrm{aB}$ & $10,91 \mathrm{aAB}$ & $11,68 \mathrm{aA}$ & $6,78 \mathrm{aC}$ \\
FA & $10,21 \mathrm{aA}$ & $6,15 \mathrm{bB}$ & $5,50 \mathrm{bB}$ & $5,72 \mathrm{bB}$ & $5,54 \mathrm{abB}$ \\
BDA & $1,99 \mathrm{cD}$ & $3,67 \mathrm{cC}$ & $9,81 \mathrm{aA}$ & $5,44 \mathrm{bB}$ & $6,74 \mathrm{aB}$ \\
V-8 & $2,64 \mathrm{cB}$ & $4,27 \mathrm{bcAB}$ & $4,91 \mathrm{bA}$ & $4,91 \mathrm{bA}$ & $4,81 \mathrm{Aa}$ \\
\hline $\mathrm{C} . \mathrm{V}=$
\end{tabular}

C.V $=9,56$

*Médias de três repetições por tratamento. Médias seguidas das mesmas letras minúsculas (colunas) e maiúsculas (linhas) não diferem entre si estatisticamente pelo teste de Tukey ao nível de $5 \%$ de probalidade. Dados transformados em $(\mathrm{X}+0,5)^{0,5}$

**BDA = batata-dextrose-ágar; $\mathrm{V}-8=$ suco V-8- $\mathrm{CaCO}_{3}$-ágar; $\mathrm{AvA}=$ flocos de aveia-ágar; FA = fubá de milho-ágar.

TABELA 3 - Fertilidade de picnídios de isolados de Lasiodiplodia theobromae em diferentes meios de cultura

\begin{tabular}{lcccccc}
\hline \hline \multicolumn{6}{c}{ Número de picnídios férteis* } \\
\hline $\begin{array}{c}\text { Meios } \\
\text { de }\end{array}$ \\
\cline { 2 - 7 } $\begin{array}{c}\text { Cultura } \\
\text { ** }\end{array}$ & $\mathbf{1}$ & $\mathbf{2}$ & $\mathbf{3}$ & $\mathbf{5}$ & $\mathbf{7}$ \\
\hline AvA & $3,78 \mathrm{aC}$ & $2,63 \mathrm{aD}$ & $4,92 \mathrm{aB}$ & 8,1 & $\mathrm{aA}$ & $1,28 \mathrm{cE}$ \\
FA & $2,31 \mathrm{bB}$ & $2,57 \mathrm{aAB}$ & $1,63 \mathrm{cC}$ & $3,18 \mathrm{bA}$ & 2,1 & $\mathrm{bBC}$ \\
$\mathrm{BDA}$ & $1,28 \mathrm{cC}$ & $1,28 \mathrm{bC}$ & $3,26 \mathrm{bB}$ & $2,64 \mathrm{cB}$ & 4,5 & $\mathrm{aA}$ \\
$\mathrm{V}-8$ & $1,79 \mathrm{bcBC}$ & $1,14 \mathrm{bC}$ & $2,29 \mathrm{bcA}$ & $2,94 \mathrm{bcA}$ & 1,9 & $\mathrm{cBC}$ \\
\hline $\mathrm{C} \cdot \mathrm{V}=9,69$
\end{tabular}

C.V $=9,69$

*Médias de três repetições por tratamento. Médias seguidas das mesmas letras minúsculas (colunas) e maiúsculas (linhas) não diferem entre si estatisticamente pelo teste de Tukey ao nível de 5\% de probalidade. Dados transformados em $(X+0,5)^{0,5}$

**BDA = batata-dextrose-ágar; V-8 = suco V-8- $\mathrm{CaCO}_{3}$-ágar; $\mathrm{AvA}=$ flocos de aveia-ágar; FA = fubá de milho-ágar

mais rápido em crescimento micelial. Uma hipótese que pode justificar isso é fato de que um fungo pode utilizar sua energia só para o crescimento, enquanto que outro se utiliza de sua energia para esporulação. Estes resultados sugerem à existência de diferenças genéticas entre os isolados quanto ao crescimento e esporulação, fato que pode ser observado nos outros aspectos estudados no presente trabalho.

\section{Influência de meios de cultura sobre as características culturais de isolados de Lasiodiplodia theobromae}

As características culturais dos oito isolados da $L$. theobromae estudados, variaram em função dos meios utilizados (Tabela 4). As variações observadas nos isolados em cada substrato foram referentes à coloração da colônia e formação dos picnídios. De um modo geral, as colônias apresentaram crescimento vigoroso, micélio aéreo, coloração branca quando novas e escuras quando mais velhas cobrindo toda a superfície da placa entre 48 e $72 \mathrm{~h}$, formando picnídios geralmente entre o $7^{\circ}$ e $9^{\circ}$ dia de incubação.

A coloração das colônias variou de branco a negro, passando pelo cinza. Observou-se que a maioria dos isolados formaram colônia de coloração brancoacinzentado, sendo esta predominante no meio CA, seguida da coloração cinza, que predominou no meio V- 8 e cinza a negro no meio AvA, independente dos isolados.

No que concerne à formação dos picnídios, verificou-se que o meio $\mathrm{CA}$ não induziu a formação destes e que os isolados 4 e 6 de (maracujá) e 8 (mamão) não produziram tais estruturas. Os meios $\mathrm{BDA}$ e V8 promoveram a formação de picnídios erupentes e dispersos no meio (Ed) e erupentes e submersos (Es) respectivamente. AvA e FA comportaram-se de maneira semelhante para todos os isolados, resultando na formação de picnídios errompentes e dispersos no meio (Ed) nos isolados 1 e 2 (caju), errompentes e submersos (Es) no isolado 3 (manga) e errompentes (Ep) nos isolados 5 (maracujá) e 7 (coco).

Em trabalho com isolados de B. theobromae provenientes de diversos hospedeiros em diferentes meios de cultura, Ram (1993) constatou também que os 10 isolados usados variaram na coloração da colônia e no crescimento micelial. As variações nas características culturais desse fungo em diferentes substratos indicam que $L$. theobromae como a grande maioria dos fungos, difere em suas características morfológicas, conforme modificações no substrato de desenvolvimento.

\section{Patogenicidade}

Os oito isolados de $L$. theobromae estudados mostraram-se patogênicos quando inoculados em frutos sadios de caju, maracujá, manga, coco e mamão, os quais exibiram sintomas entre 48 e 72 h após a inoculação, variando quanto à agressividade (Tabela 5).

Os sintomas da doença foram caracterizados pela formação de lesões úmidas que evoluíram para lesões de coloração marrom e resultaram em podridão dos frutos. Com relação à agressividade dos isolados do patógeno, verificou-se que os isolados 1 e 2 (caju) e 4 (maracujá) foram os mais agressivos aos hospedeiros, seguidos do isolado 7 (coco).

Ao se analisar a interação hospedeiros x isolados, observou-se que manga, mamão e maracujá mostraramse resistentes ao isolado 8 (mamão), sendo este, o que comportou-se de forma menos agressiva aos hospedeiros, excetuando-se coco e caju que foram altamente suscetível e suscetível, respectivamente, a este isolado. Com relação aos hospedeiros os mais suscetíveis foram mamão, maracujá e caju, sendo que mamão se comportou como altamente suscetível aos isolados 1 e 2 de (caju), 4 e 6 de (maracujá) e 7 (coco) e, resistentes ao demais; maracujá mostrou-se altamente suscetível aos isolados 1 e 2 de (caju), 6 (maracujá) e 7 (coco) e suscetível aos isolados 
Caracterização fisiológica, cultural e patogênica de diferentes isolados...

TABELA 4 - Características culturais de oito isolados de Lasiodiplodia theobromae em relação à cor da colônia e formação de picnídios em diferentes meios de cultura

\begin{tabular}{|c|c|c|c|c|c|c|c|c|c|c|}
\hline \multirow[b]{2}{*}{$\underbrace{\text { Meios }}_{\text {Isolados }}$} & \multicolumn{5}{|c|}{ Cor da colônia* } & \multicolumn{5}{|c|}{ Formação dos picnídios** } \\
\hline & BDA & $\mathrm{V}-8$ & AvA & FA & $\overline{\mathrm{CA}}$ & BDA & $\mathrm{V}-8$ & AvA & FA & $\mathbf{C A}$ \\
\hline 1 & $\mathrm{Ba}$ & $\mathrm{Ba}$ & $\mathrm{Cn}$ & $\mathrm{Cz}$ & $\mathrm{Ba}$ & Ed & Es & $\mathrm{Ed}$ & $\mathrm{Ed}$ & - \\
\hline 2 & $\mathrm{Ne}$ & $\mathrm{Cz}$ & $\mathrm{Cn}$ & $\mathrm{Ne}$ & $\mathrm{Ba}$ & Ed & Es & $\mathrm{Ed}$ & $\mathrm{Ed}$ & - \\
\hline 3 & $\mathrm{Ne}$ & $\mathrm{Cn}$ & $\mathrm{Cn}$ & $\mathrm{Ne}$ & $\mathrm{Ba}$ & $\mathrm{Ed}$ & Es & Es & Es & - \\
\hline 4 & $\mathrm{Cz}$ & $\mathrm{Ba}$ & $\mathrm{Cn}$ & $\mathrm{Ba}$ & $\mathrm{Ba}$ & - & - & - & - & - \\
\hline 5 & $\mathrm{Cn}$ & $\mathrm{Cz}$ & $\mathrm{Cz}$ & $\mathrm{Cn}$ & $\mathrm{Cz}$ & $\mathrm{Ed}$ & $\mathrm{Sb}$ & Ep & Ep & - \\
\hline 6 & $\mathrm{Cz}$ & $\mathrm{Cz}$ & $\mathrm{Ba}$ & $\mathrm{Cz}$ & $\mathrm{Cn}$ & - & - & - & - & - \\
\hline 7 & $\mathrm{Ba}$ & $\mathrm{Cz}$ & $\mathrm{Ba}$ & $\mathrm{Ba}$ & $\mathrm{Ba}$ & $\mathrm{Ed}$ & $\mathrm{Es}$ & Ep & $\mathrm{Ep}$ & - \\
\hline 8 & $\mathrm{Ne}$ & $\mathrm{Cn}$ & $\mathrm{Cn}$ & $\mathrm{Ne}$ & $\mathrm{Ne}$ & - & - & - & - & - \\
\hline
\end{tabular}

$* \mathrm{Ba}=$ branco-acinzentado; $\mathrm{Cn}=$ cinza a negro; $\mathrm{Cz}=$ cinza; $\mathrm{Ne}=$ negro.

$* * \mathrm{Ed}=$ erupentes e dispersos no meio; Es= erupentes e submersos; $\mathrm{Sb}=$ submersos; $\mathrm{Ep}=$ erupentes; - = não ocorreu.

4 e 5 (maracujá) e caju comportou-se como altamente suscetível aos isolados 4 e 5 de (maracujá), suscetível aos isolados 1 e 2 (caju), 3 (manga), 7 (coco), 8 (mamão) e medianamente resistente ao isolado 5 (maracujá).

Fato que merece destaque é o efeito dos isolados 4 e 6 (maracujá) e 8 (mamão) que apesar de não formarem estruturas reprodutivas nos meios de cultura estudados, mostraram-se virulentos quando inoculados na maioria dos hospedeiro testados, merecendo destaque o isolado 4 , que foi um dos mais agressivos.

Manga foi o hospedeiro que mostrou a maior resistência, obtendo nota 1 para quatro isolados, inclusive para o isolado 3 (manga), o que pode ser explicado devido ao fato da cultivar utilizada ('Espada'), ser uma espécie rústica, que não passou por processos de melhoramento genético, fato que foi constatado por Lima (1996), em teste de patogenicidade com diferentes cultivares e isolados de mangueira, onde verificou que as variedades 'Manguito', 'Espada' e 'Rosa', apresentaram-se como as mais resistentes ao patógeno.

Em relação ao isolado de coco, este mostrou-se altamente patogênico a mamão, maracujá, manga e caju, enquanto que para o coco, foi pouco agressivo, o que contraria os resultados de Ram (1993), o qual verificou que o isolado de folha de coqueiro foi o único agressivo ao coqueiro, não mostrando-se patogênico aos demais hospedeiros, e que nenhum dos isolados de outras culturas estudados foi patogênico ao coqueiro.

Esses resultados reportam à conclusão de que há variação quanto à patogenicidade de isolados de diferentes hospedeiros e até mesmo entre isolados da mesma cultura. A razão da variabilidade entre isolados de L. theobromae não é conhecida. Mathews \& Dodds (1986) relataram um relacionamento negativo entre virulência e a ocorrência de um fio duplo de RNA em muitos isolados deste fitopatógeno provenientes de videira.

A variação entre isolados de $L$. theobromae, observada neste trabalho e relatada por outros autores como Sousa Filho et al. (1979), Moraes et al. (1995) Lima (1996) e Ram (1996), podem ser explicadas por fatores externos, como as diferenças edafoclimáticas das regiões de onde procederam os isolados, ou internos, em que uma espécie difere de outra e um isolado dentro da mesma espécie difere de outro devido à sua composição genética. Segundo Lilly \& Barnett (1951), entre fungos a diversidade é uma norma, enquanto a uniformidade é uma exceção em relação ao comportamento entre espécies e isolados.

$\mathrm{O}$ fato do isolado de um determinado hospedeiro mostrar-se pouco agressivo para o mesmo hospedeiro, o

TABELA 5 - Patogenicidade de oito isolados de Lasiodiplodia theobromae a cinco hospedeiros*

\begin{tabular}{lccccc}
\hline \hline & \multicolumn{5}{c}{ Nota** } \\
\cline { 2 - 6 } Isolados & caju & coco & mamão & manga & maracujá \\
\cline { 2 - 6 } 1 (caju) & 3 & 4 & 4 & 3 & 4 \\
2 (caju) & 3 & 4 & 4 & 3 & 4 \\
3 (manga) & 3 & 2 & 1 & 1 & 1 \\
4 (maracujá) & 4 & 4 & 4 & 3 & 3 \\
5 (maracujá) & 4 & 2 & 1 & 1 & 3 \\
6 (maracujá) & 2 & 1 & 4 & 1 & 4 \\
7 (coco) & 3 & 2 & 4 & 4 & 4 \\
8 (mamão) & 3 & 4 & 1 & 4 & 1 \\
\hline
\end{tabular}

* Média de três repetições.

$* * 1=$ resistente; $2=$ medianamente resistente; $3=$ suscetível; $4=$ altamente suscetível. 
que foi verificado em manga, coco e mamão, pode ser explicado pela variação da cultivar, do local de origem do isolado em relação a do hospedeiro testado e da variabilidade genética entre isolados obtidos do mesmo hospedeiro.

\section{AGRADECIMENTOS}

A primeira autora agradece à Fundação de Amparo à Pesquisa do Estado de Maranhão FAPEMA pela concessão de bolsa de estudo.

\section{REFERÊNCIAS BIBLIOGRÁFICAS}

ALASOADURA, S.O. Culture studies on Botryodiplodia theobromae Pat. Mycopathologia et Mycologia Applicata 42:153160. 1970.

FREIRE, F.C.O., VIANA, F.M.P., CARDOSO, J.E. \& SANTOS, A.A. Novos hospedeiros do fungo Lasiodiplodia theobromae no estado do Ceará. Comunicado Técnico No 91 . Fortaleza. Embrapa Agroindústria Tropical, 2004.

FREIRE, F.C.O. \& CARDOSO, J.E. Doenças do coqueiro. In: Freire, F.C.O, Cardoso, J.E. \& Viana, F.M.P. (Ed.) Doenças de fruteiras tropicais de interesse agroindustrial. Brasília. Embrapa Informações Tecnológica. 2003. pp. 191 - 226.

HOLLIDAY, P. Fungus diseases of tropical crops. Cambridge. Cambridge University Press. 1980.

KUROZAWA, C. \& BALMER, E. Influencia de fatores nutricionais na produção de picnídios férteis de Septoria lycopersici Speg. Summa Phytopathologica 3:52-57. 1997.

LILLY, V.G. \& BARNETT, H.L. Physiology of the fungi. New Graw-Hill. 1951.

LIMA, J.A.S. Caracterização patogênica, fisiológica, cultural e isoesterástica de isolados de Botryodiplodia theobromae Pat., agente causal da morte descendente da mangueira (Mangifera indica L.). (Dissertação de mestrado). Recife. Universidade Federal Rural de Pernambuco. 1996.

MACHADO, A.A. Esporulação de Macrophomina phaseolina (Tass.) Goid. e variabilidade do método de inoculação de esporos em estudos de seleção de germoplasma resistente. (Disertação de Mestrado). Piracicaba. Escola Superior de Agricultura "Luiz de Queiroz"/USP. 1980.

MATHEWS, D. M. \& DODDS, J. A. The development of hypovirulence for the control of grape disease caused by Botryodiplodia theobromae. Phytopathology 76:845. 1986.
MATTOS, L. \& AMES, T. Botryodiplodia theobromae afectando manzano. Fitopatologia 21:26-32. 1986.

MENEZES, M., MUNIZ, M.F.S. \& QUEIROZ, F.M. Podridão da haste do mamoeiro "Sunrise-solo" causada por Botryodiplodia theobromae no estado de Alagoas. Summa Phytopathologica 23:44-45. 1997.

MORAES, W.S., CASTRO, H.A., LEITE, E., NAVES, R.L., CAMPOS, S.S., AMORIM, L. \& KIMURA M. Caracterização morfológica e cultural de Botryodiplodia theobromae em diferentes meios de cultura. Fitopatologia Brasileira 20:366. 1995. (Resumo)

OLUNLOYO, O.A. \& ESURUOSO, O.I. Lasiodiplodia floral shoot dieback disease of cashew in Nigeria. Plant Disease Reporter 59:176-179. 1975.

PONTE, I. I. Uma doença da ateira (Annona aquomosa) e da gravioleira (A. muricata) causada por Botryodiplodia theobromae. Fitopatologia Brasileira 10:689-690. 1985.

PRAKASSH, O. M. \& RAOOF, M. A. Dieback disease of mango (Mangifera indica), its distribuition, incidence, cause and management. Fitopatologia Brasileira 14:207-214. 1989.

PUNITHALIGAM, E. Botryodiplodia theobromae. CMI Description of pathogenic fungi and bacteriano. 519:1976.

RAM, C. Características culturais, esporulação e violência do "strain" do Botryodiplodia theobromae, agente causal da queimadas-folhas do coqueiro (Cocos nucifera). Fitopatologia Brasileira 18:143-146. 1993.

RODRIGUEZ, C. \& MATTOS, L. Muerte regressiva em mango (Mangifera indica L.) y comportamiento de cinco variedades frente al agente causal. Fitopatologia 23:41-48. 1988.

SALES JÚNIOR, R. Disseminação de Lasiodiplodia theobromae em Sementes de Graviola e de Ata no Nordeste Brasileiro: Importância e Controle. Anais, VIII Simpósio Brasileiro de Patologia de Sementes, João Pessoa, PB, 2004. pp. 88-90.

SOUSA FILHO, B.F., SANTOS FILHO, H.P. \& ROBBS, C.F. Etiologia da queima-das folhas do coqueiro. Fitopatologia Brasileira 4:5-10. 1979.

SUTTON, B.C. The Coelomycetes. Kew. Commonwealth Mycological Institute. 1980.

TAVARES, S.C.C.H. Epidemiologia e manejo integrado de Botryodiplodia theobromae - situação atual no Brasil e no mundo. Fitopatologia Brasileira 27:46-52. 2002.

TAVARES, S.C.C.H. Principais doenças da mangueira e alternativas de controle. Informações técnicas sobre a cultura da manga no Semi-Árido Brasileiro. DF. EMBRAPA-CPATSA. 1995.

TAVARES, S.C.C.H., BARRETO, D.S.B. \& AMORIM, L.R. Levantamento do comportamento de Botryodiplodia theobromae em videira na região semi-árida. Anais, XII Congresso Brasileiro de Fruticultura, Salvador, BA, 1994. pp. 933-934. 